\title{
PRESENTATION SNAPSHOT
}

\section{Cultivating the Farmers Markets of Minneapolis Collaborative}

PLACE-BASED FOOD SYSTEMS CONFERENCE: August 9-10th, 2018

\author{
Tamara Downs Schwei ${ }^{a * \dagger}$ \\ City of Minneapolis
}

\author{
Hikaru Hanawa Peterson ${ }^{\mathrm{b}}$ and Joseph J. Nowak ${ }^{\mathrm{c}}$ \\ University of Minnesota
}

\section{Presentation Abstract}

Farmers markets have operated in Minneapolis for more than 100 years. Twenty-nine markets operated in 2018 with about 800 vendors representing a range of ages, cultures, and geography. Markets are independently managed, varying in governance structure, and until recently without coordination. Collaboration among Minneapolis markets was identified as a priority in 2009 and realized in 2017 with the formation of the Farmers Markets of Minneapolis, which engaged market managers, the City of Minneapolis, the University of Minnesota, and other partners.

The 2008 launch of Homegrown Minneapolis, a citywide initiative, fostered collaborative discussions among market managers. The Minneapolis City Council adopted recommendations for markets in 2009 that included the creation of a formal means for markets to coordinate their activities. This remained a latent opportunity until 2015, when market managers with renewed interest forged a collaboration with new Homegrown Minneapolis staff and University of Minnesota-Twin Cities faculty. City and university staff time helped propel the efforts forward.

The collaboration gained momentum from the development of a market metrics project and a collaborative strategic plan and marketing campaign. The metrics project was inspired by the need for data to illustrate community impact. Following a 2016 pilot, the first season of a three-year metrics project was completed in 2017 after surveying 27 markets in Minneapolis and St. Paul. Strategic planning in 2016-2017 identified collaborative goals. The collaborative launched a marketing campaign in 2017 to establish the Farmers Markets

a* Tamara Downs Schwei has served as the City of Minneapolis food policy coordinator $\dagger$ since 2014. Tamara has a master of public policy in sustainable community and economic development. She can be contacted at Tamara.DownsSchwei@minneapolismn.gov.

† Note: The opinions expressed are those of the author and not the City of Minneapolis.

${ }^{b}$ Hikaru Hanawa Peterson is a professor of food marketing and consumer economics in the Department of Applied Economics at the University of Minnesota.

' Joseph J. Nowak is a Ph.D. student in the College of Food, Agricultural and Natural Resource Sciences at the University of Minnesota.

Submitted December 13, 2018 / Published online July 24, 2019

Citation: Downs Schwei, T., Petersen, H. H., \& Nowak, J. J. (2019). Cultivating the Farmers Markets of Minneapolis Collaborative [Presentation snapshot]. Journal of Agriculture, Food Systems, and Community Development, 9(Suppl. 1), 247-248.

https://doi.org/10.5304/jafscd.2019.091.026

Copyright (C) 2019 by the Authors. Published by the Lyson Center for Civic Agriculture and Food Systems. Open access under CC-BY license. 
of MPLS brand, supported by the City of Minneapolis and the G eneral Mills Foundation. The collaborative is currently implementing priority strategies and evaluating potential long-term governance structures.

Keywords: Metrics, Marketing, Collaboration, Partnerships, Farmers Markets

\section{Key Points:}

- The metrics project provided an opportunity to collaborate and generated trust, momentum, and valuable data. The planning team members identified a shared vision, vetted it with more than 100 stakeholders, and formalized it by adopting a strategic plan.

- The collaborative consulted with credible leaders. They held calls with researchers at the Farmers Market Coalition and the University of Wisconsin-Madison to understand their metrics program. Support from the $\mathrm{G}$ eneral Mills Foundation enabled the collaborative to enlist marketing professionals to develop a collaborative brand and marketing campaign. D ata collection protocols developed by an applied economist at the University of Minnesota guaranteed the metrics' integrity.

- D ecentralized roles and activity among market managers, organizations, and institutions created both complexity and stability for the partnership and leveraged a breadth of opportunities and resources.

\section{Conclusion}

The Farmers Markets of Minneapolis is a promising collaborative model, bolstered by city and university partnerships. Like any healthy organization, the system of collaborative relationships has required ongoing maintenance. Productivity coupled with time for informal check-ins and social time have been critical contributors to the endurance of the collaborative partnership and projects to date. Ongoing invitations to participate and flexible, adaptive roles and approaches have helped engage new partners when existing partners have left their roles.

\section{References and Resources}

City of Minneapolis. (n.d.) Homegrown Minneapolis. Retrieved January 8, 2019, from

http:/ / www.minneapolismn.gov/ sustainability/ homegrown/

Farmers Market Coalition. (2018). Farmers market metrics: Background \& history. Retrieved January 8, 2019, from https:/ / farmersmarketmetrics.guide/ background/

Farmers Markets of Minneapolis. (2017). Farmers Markets of MPLS. Retrieved January 8, 2019, from http:/ / farmersmarketsofmpls.org/

\section{Acknowledgments}

Collaborating partners have included Maggi Adamek, Martha Archer, Alyssa Banks, Amanda Chavez, Alexandra Cortes, Elizabeth Day, Tabitha Fischer, Miguel G oebel, Kristen Klingler, Sarah Knoss, Emily Lund, Helene Murray, Pat Nelson, D avid Nicholson, D eVon Nolen, Jenna Y eakle, and Mai Yang.

\section{Funding Disclosure}

Funding support has been provided by the City of Minneapolis, Funders Network, General Mills Foundation, G reater Twin Cities United Way, McKnight Foundation, Minnesota D epartment of Agriculture, Minnesota D epartment of Health Statewide Health Improvement Partnership, University of Minnesota, and USD A Agricultural Marketing Service (\#16FMPPMN0025). 